\title{
Morbidity follow up study of BASF employees exposed to 2,3,7,8-tetrachlorodibenzo-p-dioxin (TCDD) after a 1953 chemical reactor incident
}

Occupational Medical and Health Protection Department, BASF Aktiengesellschaft, D67056 Ludwigshafen, Germany

A Zober

P Messerer

Medical Department, BASF Corporation, Parsippany NJ, USA M Gerald Ott

Correspondence to: Professor A Zober

Accepted for publication 18 March 1994

Andreas Zober, M Gerald Ott, Peter Messerer

\begin{abstract}
Objective-The aim was to examine the long term morbidity experience of men exposed to $2,3,7,8$-tetrachlorodibenzo-pdioxin (TCDD).

Methods-A retrospective cohort morbidity study of 158 men first exposed to TCDD between 17 November 1953 and 16 November 1954 subdivided by chloracne state and back calculated TCDD blood lipid concentration, and 161 referents. Cause specific illness absence and admissions to hospital were examined between 1953 and 1989.
\end{abstract}

Results-On an ever or never basis, thyroid disease and appendicitis were diagnosed more often in the study group; these diseases were not differentially distributed by chloracne state, but were increased in the high TCDD subgroup. An 18\% increase in total illness episodes was also seen $(p=0 \cdot 002)$; illness rates increased with severity of chloracne and higher TCDD concentration within the chloracne subgroup. There were increases in infectious and parasitic diseases (primarily ill defined intestinal infections), disorders of the peripheral nervous system and sense organs, upper respiratory tract infections, and other skin diseases. Several of these increases correlated with chloracne state and infectious disease episodes increased with higher TCDD concentration as well. Occurrences of mental disorders correlated with severity of chloracne, but not TCDD concentration. Benign and unspecified neoplasms were marginally increased in the severe chloracne and high TCDD subgroups. Chronic liver disease was marginally increased in the high TCDD subgroup. Findings relative to occurrence of ulcers, chronic lung disease, and kidney and metabolic disorders were unremarkable.

Discussion-For various conditions, increased illness episodes were seen among TCDD exposed employees compared with referents and were associated with either or both chloracne severity and back calculated TCDD concentration. The results are derived from insurance data; hence, it is possible that heightened awareness and personal health concerns led to greater utilisation of medical services in the exposed group. The findings based on TCDD concentration should be less subject to this potential bias.

(Occup Environ Med 1994;51:479-486)

Key words: TCCD, thyroid disease, infectious disease

On 17 November 1953, within a few months of its start up, a BASF trichlorophenol unit experienced an uncontrolled decomposition reaction. Fumes escaping from the affected autoclave condensed on surfaces in the immediate work area of the enclosed facility. In a matter of days, workmen engaged in clean up efforts began to experience acnegenic responses as well as other signs and symptoms of toxicity. ${ }^{1-3}$ The agent most likely to have caused these responses was not determined until 1957 when 2,3,7,8-tetrachlorodibenzop-dioxin (TCDD) was chemically identified as a byproduct of trichlorophenol production and was shown to be a potent inducer of chloracne. ${ }^{4}$

As well as the clinical reports, follow up studies were conducted to evaluate the mortality experience of exposed employees. ${ }^{56}$ The eventual study population included persons who assisted in demolishing the autoclave portion of the unit in 1968-9 as well as those assigned to prior assessment and clean up activities. Although other materials were produced by the unit after the accident, trichlorophenol production was not resumed.

Beginning in 1988, TCDD concentrations were determined in blood lipids for 138 surviving members of the accident cohort. From these data and detailed exposure descriptions, a regression model was developed to assess the contribution of various exposure factors to each employee's overall TCDD burden. ${ }^{7}$ Cumulative TCDD concentrations, back calculated to the time of exposure, have now been estimated for all cohort members from these model results. ${ }^{78}$ Concentrations of higher chlorinated dioxins were not increased beyond background values.?

Prior studies indicate that TCDD exposed people may experience a wide range of symptoms shortly after exposure and that the liver, kidneys, peripheral, and central nervous system, immune system, and skin may all be targets of injury. ${ }^{9}$ Complaints have included headache, dizziness, nausea, severe muscle pain, fatigue, nervousness and irritability, dyspnoea, decreased libido, and intolerance to cold. ${ }^{9}$ Other than a persistent acne, there has 
been little evidence of lasting or progressive non-carcinogenic effects.

New health legislation enacted in Germany during 1990 has enabled insurers to share anonymous medical diagnosis data with occupational medical departments as long as these data cannot be linked back to specific subjects. From an epidemiological perspective, use of this data resource offers several advantages. Firstly, it can provide morbidity information over a long period. Secondly, the diagnoses are generally based on independent external evaluations without detailed knowledge of exposure, thus minimising the potential for observation bias. There are inherent disadvantages as well. Because of considerations of confidentiality, it is not possible to confirm diagnoses independently and potential confounding factors such as age can only be considered through prior selection of comparable referents. Secondly, the availability of data is restricted to those insured through the health insurance fund, the Betriebskrankenkasse (BKK). Data are accessible for retirees, but not for contract workers or workers who left the company for other jobs. Finally, claims data are provided for admissions to hospital and absences from work due to illness but these may not be available for less debilitating conditions.

The current study objectives were to describe the long term morbidity experience of TCDD exposed workers and to determine if exposed employees experienced higher cause specific morbidity than comparable non-exposed employees. A corollary objective was to evaluate the usefulness of medical insurance data as a means of assessing possible work related health effects. The observation period was from 17 November 1953 to 31 December, 1989 and the indices of morbidity were the coded diagnoses and conditions reported in the medical insurance claims of employees.

\section{Population and methods}

STUDY GROUP

Study participants were chosen from the 247

TCDD exposed workers reported in the latest cohort mortality study ${ }^{6}$ plus seven employees subsequently identified as belonging to the accident cohort. ${ }^{7}$ To permit analysis of morbidity by time since exposure and, at the same time, protect participant anonymity, the target population was restricted to the 175 cohort members whose first TCDD contact occurred within one year of the accident. The highest potential for exposure to TCDD undoubtedly occurred during this time as confirmed later by biomonitoring data. ${ }^{7}$ The final study group consisted of 158 men after exclusion of four women employees because of anonymity considerations and 13 male employees who were never BKK members. Most of the excluded employees held managerial or professional positions.

The study group was divided into three subgroups based on chloracne state as determined from a prior review of occupational medical records. ${ }^{6}$ Subgroup I consisted of 52 workers whose chloracne was classified as extensive or severe. Subgroup II consisted of 61 workers, 50 with moderate chloracne and 11 with a diagnosis of "erythema" at the time of exposure but no chloracne. Finally, subgroup III comprised 45 men with no evidence of chloracne or "erythema". These groups were similar in size and large enough to protect the anonymity of subjects. The exposure assessment, referred to previously, enabled a further subdivision of the study group according to model based TCDD blood lipid concentrations back calculated to the time of exposure. ${ }^{7}$ Thus each of the chloracne subgroups was also subdivided with 1000 parts per trillion (ppt) as a cut off point. In total, 73 members of the study group had back calculated TCDD values of $>1000 \mathrm{ppt}, 33$ in the severe, 29 in the moderate, and 11 in the no chloracne subgroups.

\section{REFERENTS}

The referent group was selected from a computerised data base of all persons who either worked at this large manufacturing complex after 1969 or who retired before 1970 . In 1989, the complex employed more than 50000 workers. General site employees were presumed not to have experienced TCDD exposures above background. Limited sampling of six workers gave TCDD blood lipid concentrations averaging $3.3 \mathrm{ppt}$. Also, 42 samples from long term employees not included in the study, but who were assigned duties in and around the affected building between 1960 and 1968, averaged only 5.1 ppt. The referent pool was restricted to men hired before November 1953 and to people with German or German-French surnames as this was the case for all study group members. Finally, managerial and professional employees were excluded because less than $10 \%$ of the exposed employees came from these positions and BKK membership is less common in high income groups. Among hourly employees, BKK membership is over $95 \%$.

The referent selection process was carried out by computer with random selection without replacement based on birth year distribution frequencies after selecting a pool of eligible candidates. The process was performed separately for each of the three chloracne subgroups, but not separately for the TCDD concentration subgroups. This led to referents that were frequency but not individually matched on age within each chloracne subgroup. Referents who were not BKK members were replaced. Three workers in the study group were shown not to have been BKK members only after referent selection had been completed. Hence, in the "no chloracne" subgroup, there were three more referents than study group members.

Several notable factors could not be controlled through the selection procedure. Firstly, there were 43 study group members who left active employment before 1970 including 13 who died before 1970. The corresponding referent group included only 27 
people who left employment before 1970, all presumably due to retirement. Six of these men had died before 1970. Secondly, a number of study group members were contract workers in 1953 and only later became company employees. Thus these workers would not have been BKK members until 1954 or later, whereas all referents were company employees as of November 1953.

\section{DATA COLLECTION}

Separate lists containing the names, employee ID numbers, and birth dates were provided to insurance personnel for each study and referent subgroup. Insurance folders were then reviewed and the following information was provided back to the medical department by subgroup: (a) a numerical personal identifier assigned by the Insurance Department, $(b)$ for each reported illness absence or admission to hospital, from one to five diagnoses abstracted from the physician's report and coded according to the International Classification of Diseases, 9th revision, (ICD-9), and (c) an indication of retirement state and period (1953-9, 1960-9, 1970-89) in which the illness episode occurred.

The BKK separately provided an annual frequency tabulation of the number of BKK members within each study and referent subgroup and also provided an annual tabulation of the number of retirees in each group. This information was used for calculation of personyears of observation by group and time period. As retiree episodes were limited to admissions to hospital, it was expected that fewer episodes would be reported after retirement.

\section{STATISTICAL APPROACH}

In general, the outcome measure for acute and non-specific conditions was the number of illness episodes per time period per employee, whereas chronic disease conditions were classified on an ever or never basis. When multiple diagnoses were reported, each was associated with the specific episode in the analyses. The selection of ICD categories was made a priori and was based largely on disease entities postulated to be related to TCDD exposure in the medical literature. Appendicitis is an exception in that this category was included on the basis of ICD frequency tabulations suggesting an unusual distribution with respect to exposure state. A second exception was made for the category poisonings by non-medicinals. Based on review of the text and time of the diagnoses, it was realised that most of these episodes related to the immediate consequences of overexposure to TCDD after the accident.

Comparisons of disease conditions coded on an ever or never basis were made with Fisher's exact test. An approximate statistical test for detecting differences in illness rates between the exposed and referent groups was based on a comparison of directly standardised rates. Rates were standardised by period but not by employment state as the percentage of person-years among retirees was rela- tively constant across employee subgroups. The standard population was chosen to be the combined study and referent groups. For a given employee subgroup, the standardised illness episode rate can be expressed as $\Sigma_{i}\left(P_{i}\left(\Sigma_{i j} n_{i j}\right) / p_{i}\right)$ where $P_{i}$ represents the proportion of total person-years assigned to the $i^{\text {th }}$ stratum within the standard population and where $n_{i j}$ and $p y_{i}$ represent the number of episodes reported for the $j^{\text {th }}$ person in the $i^{\text {th }}$ stratum and the observed person-years in the $i^{\text {th }}$ stratum, respectively. The variance of $n_{i j}$ is estimated as the variance of episode counts among subjects within the $\mathrm{i}^{\text {th }}$ stratum. The comparison of two rates was based on normal distribution assumptions by a $\mathrm{z}$ score statistic formed as the difference in rates over the square root of the sum of the rate variances.

\section{Results}

The mean ages of the TCDD exposed and referent groups in 1954 were 33.0 (SD 10.9) and $33.1(11.0)$ years respectively. The age distributions across chloracne subgroups were also similar with the average age differing by no more than 1.9 years. The mean duration of insurance coverage varied from $25 \cdot 2$ to $31 \cdot 8$ years across subgroups. The shorter mean coverage among exposed workers ( $27 \cdot 8$ years) compared with referents ( 30.7 years) resulted from greater membership of referents in the BKK as of late 1953 and fewer exposed workers remaining covered near the end of the observation period. For the moderate chloracne subgroup, 12 fewer exposed than referent workers were BKK members in 1989.

Geometric mean TCDD blood lipid concentrations back calculated to date of exposure were lowest for the no chloracne (148 $\mathrm{ppt}$ ) and highest for the severe chloracne subgroup (1118 ppt). The broad range in the 20 th to 80 th percentile concentrations (20-1279 ppt for the no chloracne group and 493-2955 ppt for the severe chloracne subgroup) shows considerable overlap in TCDD exposures across subgroups. The geometric mean TCDD concentration among the 96 people from the total cohort who were excluded from the present morbidity study was $7.3 \mathrm{ppt}$, considerably less than that of even the no chloracne subgroup exposed to TCDD within one year of the accident.

\section{ANALYSES BY EXPOSURE AND CHLORACNE} STATE

Table 1 shows the percentage of exposed and referent group members ever diagnosed with selected conditions. Higher percentages of exposed workers were diagnosed with diseases of the thyroid and appendicitis. For these disease categories the differences between the exposed and referent groups were relatively constant across chloracne subgroups. Only one condition, diabetes mellitus, was found significantly less often in the exposed group than among referents. This finding was largely due to low percentages of workers with diabetic conditions in the no chloracne and moderate chloracne subgroups. A significantly 
Table $1 \%$ of TCDD and referent group members ever with selected morbidity diagnoses by chloracne state of TCDD group (1953-89)

\begin{tabular}{|c|c|c|c|c|c|c|c|c|}
\hline \multirow[b]{3}{*}{ Disease category (ICD-9) } & \multicolumn{8}{|c|}{ People ever with diagnosis (\%) } \\
\hline & \multicolumn{2}{|c|}{ Total group } & \multicolumn{2}{|c|}{ No chloracne } & \multicolumn{2}{|c|}{ Moderate chloracne } & \multicolumn{2}{|c|}{ Severe chloracne } \\
\hline & $\begin{array}{l}T C D D \\
(n=158)\end{array}$ & $\begin{array}{l}\text { Referents } \\
(n=161)\end{array}$ & $\begin{array}{l}T C D D \\
(n=45)\end{array}$ & $\begin{array}{l}\text { Referents } \\
(n=48)\end{array}$ & $\begin{array}{l}T C D D \\
(n=61)\end{array}$ & $\begin{array}{l}\text { Referents } \\
(n=61)\end{array}$ & $\begin{array}{l}T C D D \\
(n=52)\end{array}$ & $\begin{array}{l}\text { Referents } \\
(n=52)\end{array}$ \\
\hline $\begin{array}{l}\text { Malignant neoplasms } \\
(140-208) \\
\text { Benign and unspecified }\end{array}$ & $14 \cdot 6$ & $11 \cdot 2$ & $8 \cdot 9$ & $8 \cdot 3$ & $19 \cdot 7$ & $13 \cdot 1$ & $13 \cdot 5$ & $11 \cdot 5$ \\
\hline $\begin{array}{l}\text { neoplasms (210-229, } \\
235-239)\end{array}$ & $19 \cdot 6$ & $16 \cdot 8$ & $15 \cdot 6$ & $18 \cdot 8$ & $18 \cdot 0$ & $19 \cdot 7$ & $25 \cdot 0$ & $11 \cdot 5$ \\
\hline $\begin{array}{l}\text { Diseases of the thyroid } \\
(240-246) \\
\text { Diabetes mellitus (250) }\end{array}$ & $\begin{array}{l}7 \cdot 0^{\star} \\
6 \cdot 3\end{array}$ & $\begin{array}{c}1 \cdot 2 \\
14 \cdot 3^{\star}\end{array}$ & $\begin{array}{l}6 \cdot 7 \\
2 \cdot 2\end{array}$ & $\begin{array}{c}0 \cdot 0 \\
18 \cdot 8^{\star}\end{array}$ & $\begin{array}{l}8 \cdot 2 \\
4 \cdot 9\end{array}$ & $\begin{array}{r}1.6 \\
11.5\end{array}$ & $\begin{array}{r}5 \cdot 8 \\
11 \cdot 5\end{array}$ & $\begin{array}{r}1 \cdot 9 \\
13 \cdot 5\end{array}$ \\
\hline $\begin{array}{l}\text { Disorders of lipid metabolism } \\
(272)\end{array}$ & $2 \cdot 5$ & 0.6 & 0.0 & 0.0 & $1 \cdot 6$ & $1 \cdot 6$ & $5 \cdot 8$ & $0 \cdot 0$ \\
\hline $\begin{array}{l}(410-414) \\
\text { Ulcer }(531-534) \\
\text { Appendicitis }(540-543) \\
\text { Chronic liver disease }\end{array}$ & $\begin{array}{l}43 \cdot 0 \\
15 \cdot 8 \\
16 \cdot 5^{\star \star}\end{array}$ & $\begin{array}{r}41 \cdot 0 \\
23 \cdot 0 \\
5 \cdot 6\end{array}$ & $\begin{array}{r}51 \cdot 1 \\
2 \cdot 2 \\
20 \cdot 0\end{array}$ & $\begin{array}{c}60 \cdot 4 \\
18 \cdot 8^{\star} \\
6 \cdot 3\end{array}$ & $\begin{array}{l}39 \cdot 3 \\
26 \cdot 2 \\
14 \cdot 8\end{array}$ & $\begin{array}{r}29 \cdot 5 \\
21 \cdot 3 \\
4 \cdot 9\end{array}$ & $\begin{array}{l}40 \cdot 4 \\
15 \cdot 4 \\
15 \cdot 4\end{array}$ & $\begin{array}{r}36 \cdot 5 \\
28 \cdot 9 \\
5 \cdot 8\end{array}$ \\
\hline $\begin{array}{l}(570-573) \\
\text { Nephritis and nephrosis }\end{array}$ & $26 \cdot 0$ & $23 \cdot 0$ & $15 \cdot 6$ & $20 \cdot 8$ & $29 \cdot 5$ & $24 \cdot 6$ & $30 \cdot 8$ & $23 \cdot 1$ \\
\hline $\begin{array}{l}(580-589) \\
\text { Calculus of kidney and ureter }\end{array}$ & $5 \cdot 1$ & $5 \cdot 0$ & $4 \cdot 4$ & $8 \cdot 3$ & $6 \cdot 6$ & $3 \cdot 3$ & $3 \cdot 9$ & $3 \cdot 9$ \\
\hline $\begin{array}{l}(592) \\
\text { Diseases of the sebaceous }\end{array}$ & $11 \cdot 4$ & $9 \cdot 9$ & $11 \cdot 1$ & $6 \cdot 3$ & $4 \cdot 9$ & $11 \cdot 5$ & $19 \cdot 2$ & $11 \cdot 5$ \\
\hline glands (706) & $10 \cdot 1$ & $8 \cdot 7$ & 0.0 & $8 \cdot 3$ & $6 \cdot 6$ & $13 \cdot 1$ & $23 \cdot 1^{\star \star}$ & 3.9 \\
\hline
\end{tabular}

${ }^{\star} p<0.05 ;{ }^{\star \star} p<0.01$ by Fishers two sided exact test.

lower frequency of ulcers was reported in the no chloracne subgroup compared with referents and a marginally lower frequency of ulcers was reported in the severe chloracne subgroup. There was higher disability due to diseases of the sebaceous glands in the severe chloracne group, as expected. Benign and unspecified neoplasms were marginally increased in the severe chloracne subgroup with a positive diagnosis made for $25 \%$ of all subgroup members.

Table 2 summarises illness rates by exposure subgroup, time period, and employment (active $v$ retired). There was a total of 10335 illness absences or admissions to hospital among the 319 men studied. Illness rates were much lower among retired employees as only admissions to hospital have been reported. Less than $13 \%$ of the person-years of observation occurred, however, among retirees. During active employment, illness rates declined over time in both the exposed and referent groups. Rates were highest in the severe chloracne subgroup for each time period and after retirement as well. An incon- sistent pattern was found for the no chloracne and moderate chloracne subgroups.

Table 3 shows cause specific illness rates. The directly standardised rates were $18 \%$ higher in the TCDD group for total episodes $(p=0.002)$ and were also statistically increased for the following categories: disorders of peripheral nervous system and sense organs, upper respiratory tract infections, other skin diseases, injury, and poisonings by non-medicinals. The illness rate was also marginally increased for infectious and parasitic diseases $(p=0.067)$. A single diagnosis entry was reported for $78.0 \%$ of the referent and $81.2 \%$ of the TCDD group episodes. Three or more diagnoses were provided for $3.7 \%$ of the referent and $2.9 \%$ of the TCDD group episodes. Multiple diagnoses were more likely to be reported in later years of the study.

Table 4 summarises subgroup comparisons. Only disease categories with one or more statistically significant findings are presented. All but one of the findings pertain to the severe chloracne subgroup. Overall illness rates were $46 \%$ higher in this subgroup

Table 2 Illness episodes per 100 person-years by employment state, time period, and exposure group

\begin{tabular}{|c|c|c|c|c|c|c|c|c|c|c|}
\hline \multirow[b]{3}{*}{ Exposure group } & \multicolumn{8}{|c|}{ Active employment } & \multirow{2}{*}{\multicolumn{2}{|c|}{$\frac{\text { Retired }}{\text { Total }}$}} \\
\hline & \multicolumn{2}{|c|}{ Total period } & \multicolumn{2}{|c|}{ 1953-9 } & \multicolumn{2}{|c|}{$1960-9$} & \multicolumn{2}{|c|}{$1970-89$} & & \\
\hline & Rate & $(T E)$ & Rate & $(T E)$ & Rate & $(T E)$ & Rate & $(T E)$ & Rate & $(T E)$ \\
\hline $\begin{array}{l}\text { Total cohort: } \\
\text { TCDD }(n=158) \\
\text { Referents }(n=161)\end{array}$ & $\begin{array}{l}132.9 \\
111 \cdot 7\end{array}$ & $\begin{array}{l}(5057) \\
(4848)\end{array}$ & $\begin{array}{l}156 \cdot 2 \\
133 \cdot 5\end{array}$ & $\begin{array}{l}(1338) \\
(1258)\end{array}$ & $\begin{array}{l}145 \cdot 1 \\
112 \cdot 1\end{array}$ & $\begin{array}{l}(1827) \\
(1634)\end{array}$ & $\begin{array}{l}111.9 \\
100.8\end{array}$ & $\begin{array}{l}(1892) \\
(1956)\end{array}$ & $\begin{array}{l}42 \cdot 1 \\
30 \cdot 8\end{array}$ & $\begin{array}{l}(244) \\
(186)\end{array}$ \\
\hline $\begin{array}{l}\text { No chloracne: } \\
\text { TCDD }(n=45) \\
\text { Referents }(n=48)\end{array}$ & $\begin{array}{l}104 \cdot 5 \\
109 \cdot 6\end{array}$ & $\begin{array}{l}(1206) \\
(1455)\end{array}$ & $\begin{array}{l}120 \cdot 9 \\
102 \cdot 9\end{array}$ & $\begin{array}{l}(286) \\
(300)\end{array}$ & $\begin{array}{l}115 \cdot 1 \\
105 \cdot 9\end{array}$ & $\begin{array}{l}(405) \\
(483)\end{array}$ & $\begin{array}{r}91.0 \\
115.8\end{array}$ & $\begin{array}{l}(515) \\
(672)\end{array}$ & $\begin{array}{l}19 \cdot 1 \\
19 \cdot 0\end{array}$ & $\begin{array}{l}(31) \\
(38)\end{array}$ \\
\hline $\begin{array}{l}\text { Moderate chloracne: } \\
\text { TCDD }(n=61) \\
\text { Referents }(n=61)\end{array}$ & $\begin{array}{l}138 \cdot 1 \\
120 \cdot 0\end{array}$ & $\begin{array}{l}(1756) \\
(1873)\end{array}$ & $\begin{array}{l}155 \cdot 7 \\
163 \cdot 1\end{array}$ & $\begin{array}{l}(520) \\
(552)\end{array}$ & $\begin{array}{l}151 \cdot 6 \\
128.5\end{array}$ & $\begin{array}{l}(705) \\
(674)\end{array}$ & $\begin{array}{r}112 \cdot 3 \\
92 \cdot 8\end{array}$ & $\begin{array}{l}(531) \\
(647)\end{array}$ & $\begin{array}{l}40 \cdot 8 \\
34 \cdot 2\end{array}$ & $\begin{array}{r}(108) \\
(81)\end{array}$ \\
\hline $\begin{array}{l}\text { Severe chloracne: } \\
\text { TCDD }(n=52) \\
\text { Referents }(n=52)\end{array}$ & $\begin{array}{l}151 \cdot 9 \\
104 \cdot 8\end{array}$ & $\begin{array}{l}(2095) \\
(1520)\end{array}$ & $\begin{array}{l}186 \cdot 0 \\
130 \cdot 1\end{array}$ & $\begin{array}{l}(532) \\
(406)\end{array}$ & $\begin{array}{l}162 \cdot 2 \\
100 \cdot 1\end{array}$ & $\begin{array}{l}(717) \\
(477)\end{array}$ & $\begin{array}{r}129.9 \\
96.2\end{array}$ & $\begin{array}{l}(846) \\
(637)\end{array}$ & $\begin{array}{l}68.9 \\
39.9\end{array}$ & $\begin{array}{r}(105) \\
(67)\end{array}$ \\
\hline
\end{tabular}


Table 3 Illness episodes per 100 person-years for selected disease categories (1953-89)

\begin{tabular}{|c|c|c|c|}
\hline \multirow[b]{2}{*}{ Disease category (ICD-9)* } & \multicolumn{3}{|c|}{ Episodes per 100 person yearst } \\
\hline & $\begin{array}{l}T C D D \\
(n=158)\end{array}$ & $\begin{array}{c}\text { Referents } \\
(n=161)\end{array}$ & p Value \\
\hline $\begin{array}{l}\text { Total episodes } \\
\text { Infectious and parasitic diseases (001-139) } \\
\text { Mental disorders (290-317) } \\
\text { Disorders of the central nervous system (320-349) } \\
\text { Disorders of peripheral nervous system and sense organs } \\
\text { (350-389, 781) } \\
\text { Disorders of circulatory system except ischaemic heart } \\
\text { disease (392-404, 415-459) } \\
\text { Total respiratory disease }(460-519) \\
\text { Upper respiratory tract infections (460-478) } \\
\text { Pneumonia and influenza (480-487) } \\
\text { Chronic obstructive pulmonary disease }(490-496) \\
\text { Disorders of stomach and duodenum }(535-537) \\
\text { Diseases of intestine and peritoneum }(555-569) \\
\text { Other skin diseases (680-705, 707-709, 782) } \\
\text { Arthropathies (710-719) } \\
\text { Disorders of soft tissue (728-729) } \\
\text { Symptoms and ill defined conditions }(780-799) \\
\text { Injury (800-959) } \\
\text { Poisonings by non-medicinals }(980-989)\end{array}$ & $\begin{array}{r}120 \cdot 7 \\
3 \cdot 0 \\
2 \cdot 6 \\
0 \cdot 6 \\
3 \cdot 2 \\
\\
10 \cdot 3 \\
33 \cdot 7 \\
12 \cdot 0 \\
17 \cdot 4 \\
8 \cdot 0 \\
5 \cdot 5 \\
3 \cdot 8 \\
6 \cdot 7 \\
4 \cdot 7 \\
2 \cdot 1 \\
5 \cdot 8 \\
19 \cdot 5 \\
0 \cdot 8\end{array}$ & $\begin{array}{r}101 \cdot 9 \\
2 \cdot 2 \\
2 \cdot 4 \\
0 \cdot 5 \\
1 \cdot 8 \\
\\
9 \cdot 4 \\
31 \cdot 0 \\
9 \cdot 0 \\
18 \cdot 8 \\
7 \cdot 5 \\
4 \cdot 8 \\
3 \cdot 1 \\
3 \cdot 7 \\
3 \cdot 6 \\
1 \cdot 9 \\
5 \cdot 5 \\
15 \cdot 7 \\
0 \cdot 3\end{array}$ & $\begin{array}{l}0.002 \\
0.067 \\
0.704 \\
0.912 \\
\\
0.018 \\
\\
0.488 \\
0.215 \\
0.003 \\
0.078 \\
0.306 \\
0.395 \\
0.202 \\
0.001 \\
0.180 \\
0.608 \\
0.624 \\
0.008 \\
0.003\end{array}$ \\
\hline
\end{tabular}

*When multiple diagnoses are reported for an episode, each represented disease category is counted for the episode.

tRates directly standardised to the overall distribution of person years by time period. compared with referents. More than twofold increases were seen for several disease categories including infectious and parasitic diseases. Total respiratory disease was increased by $35 \%$.

\section{ANALYSES BY BACK CALCULATED TCDD \\ CONCENTRATION}

Secondary analyses were performed to examine the possible impact of high TCDD concentration $(\geqslant 1000 \mathrm{ppt})$ on illness rates based on comparisons with both the low TCDD subgroup and referents. Frequency matching by age was not possible in these analyses and there were age differences among the groups. By contrast with a mean age of $33 \cdot 1$ years among all referents in 1954, the average age of the high TCDD subgroup was $35 \cdot 5$ years and that of the low TCDD subgroup was $30 \cdot 8$ years. The highest mean age ( $37 \cdot 4$ years) was for the 29 men in the subgroup with moderate

Table 4 Illness episodes per 100 person-years by exposure subgroup for disease categories with one or more statistical findings $(p<0.05)$

\begin{tabular}{|c|c|c|c|c|c|c|}
\hline \multirow[b]{3}{*}{ Disease category $(I C D-9) \dagger$} & \multicolumn{6}{|c|}{ Episodes per 100 person-years $\ddagger$} \\
\hline & \multicolumn{2}{|c|}{ No chloracne } & \multicolumn{2}{|c|}{ Moderate chloracne } & \multicolumn{2}{|c|}{ Severe chloracne } \\
\hline & $T C D D$ & Referents & $T C D D$ & Referents & $T C D D$ & Referents \\
\hline $\begin{array}{l}\text { Total episodes } \\
\text { Infectious and parasitic diseases (001-139) } \\
\text { Mental disorders }(290-317)\end{array}$ & $\begin{array}{l}95 \cdot 5 \\
2 \cdot 0 \\
1 \cdot 6\end{array}$ & $\begin{array}{l}97 \cdot 7 \\
2 \cdot 8 \\
2 \cdot 6\end{array}$ & $\begin{array}{l}118 \cdot 4 \\
2 \cdot 8 \\
2 \cdot 8\end{array}$ & $\begin{array}{l}109 \cdot 4 \\
2 \cdot 2 \\
2 \cdot 9\end{array}$ & $\begin{array}{l}143 \cdot 7^{\star \star} \\
4 \cdot 1^{\star \star} \\
3 \cdot 2^{\star}\end{array}$ & $\begin{array}{l}98 \cdot 0 \\
1 \cdot 7 \\
1 \cdot 5\end{array}$ \\
\hline $\begin{array}{l}\text { Disorders of peripheral nervous system and sense } \\
\text { organs }(350-389,781) \\
\text { Total respiratory disease }(460-519) \\
\text { Upper respiratory tract infections }(460-478) \\
\text { Chronic obstructive pulmonary disease }(490-496) \\
\text { Other skin disease }(680-705,707-709,782) \\
\text { Poisonings by non-medicinals }(980-989)\end{array}$ & $\begin{array}{l}1 \cdot 9 \\
28 \cdot 8 \\
8 \cdot 4 \\
6 \cdot 7 \\
4 \cdot 5 \\
0 \cdot 4\end{array}$ & $\begin{array}{l}2 \cdot 1 \\
32 \cdot 4 \\
9 \cdot 1 \\
9 \cdot 1 \\
4 \cdot 1 \\
0 \cdot 1\end{array}$ & $\begin{array}{l}3 \cdot 0 \\
30 \cdot 5 \\
11 \cdot 1 \\
6 \cdot 5 \\
4 \cdot 6^{\star \star} \\
0 \cdot 8\end{array}$ & $\begin{array}{l}1 \cdot 8 \\
30 \cdot 7 \\
9 \cdot 5 \\
6 \cdot 9 \\
2 \cdot 5 \\
0 \cdot 4\end{array}$ & $\begin{array}{l}4 \cdot 4^{\star} \\
40 \cdot 8^{\star} \\
15 \cdot 8^{\star \star} \\
10 \cdot 8^{\star} \\
10 \cdot 5^{\star \star} \\
1 \cdot 3^{\star \star}\end{array}$ & $\begin{array}{l}1 \cdot 6 \\
30 \cdot 2 \\
8 \cdot 2 \\
6 \cdot 7 \\
4 \cdot 7 \\
0 \cdot 2\end{array}$ \\
\hline
\end{tabular}

${ }^{\star} \mathrm{p}<0.05 ;{ }^{\star \star} \mathrm{p}<0.01$.

tWhen multiple diagnoses are reported for an episode, each represented disease category is counted for the episode.

$\ddagger$ Rates directly standardised to the overall distribution of person-years by time period.

Table 5 Illness episodes per 100 person-years for selected disease categories (1953-89)

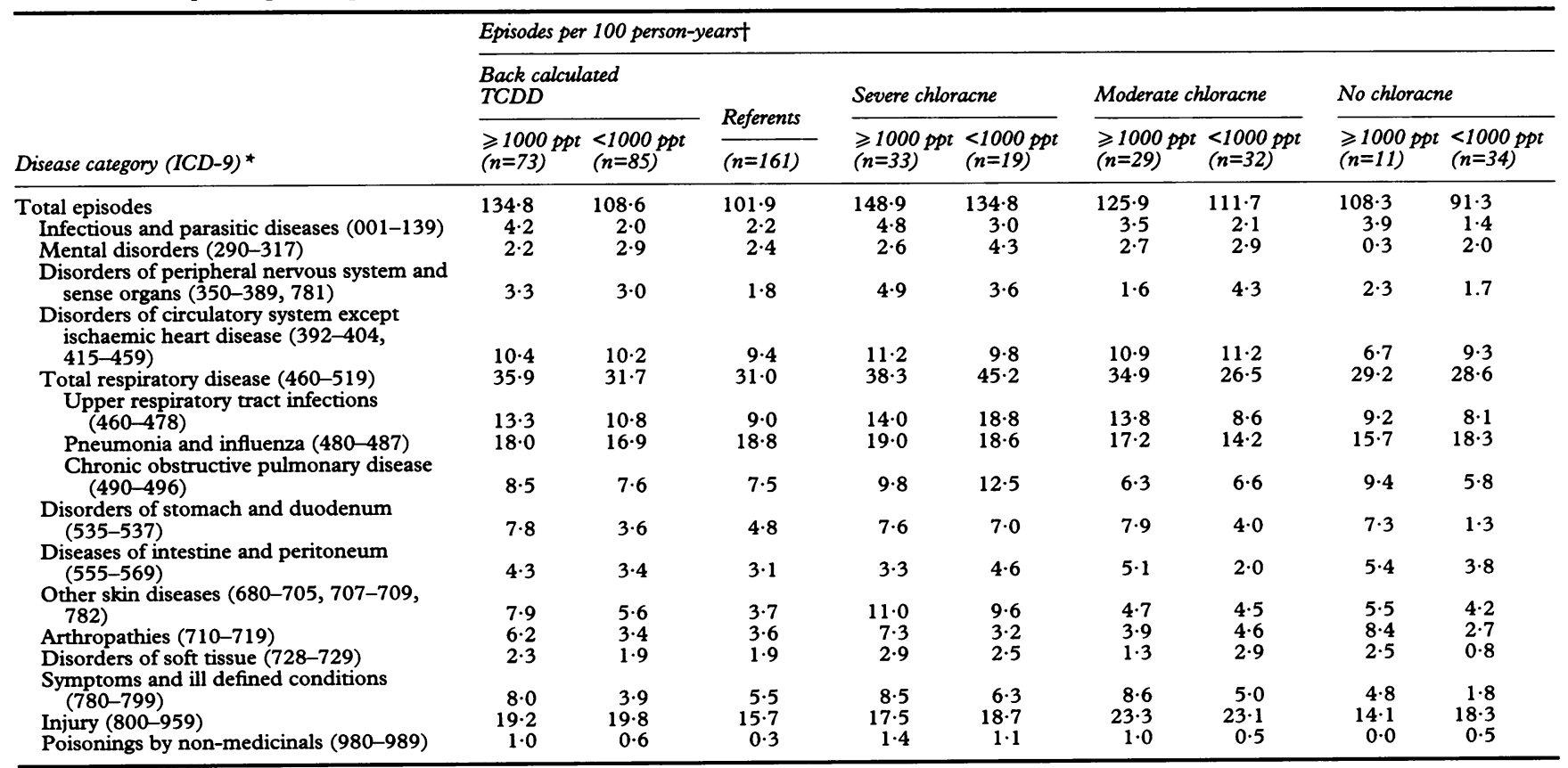

‡When multiple diagnoses are reported for an episode, each represented disease category is counted for the episode.

tRates directly standardised to the overall distribution of person years by time period (no age standardisation was possible). 
chloracne and high TCDD concentrations. These age differences indirectly reflect our prior finding that occurrence and severity of chloracne is greater among younger employees after controlling for TCDD concentration. ${ }^{7}$ Bond et al (1989) had previously shown that risk of chloracne was highest among men under age $25 .^{10}$

The percentage of those ever diagnosed with diseases of the thyroid was $8.2 \%$ (six cases) in the high TCDD subgroup, $v 5.9 \%$ in the low TCDD subgroup and $1 \cdot 2 \%$ among referents. A single case of thyroid adenoma also occurred in a person with high TCDD exposure and severe chloracne. There were 14 cases of appendicitis in the high TCDD $(19.2 \%)$ group $v 12$ cases in the low TCDD group $(14 \cdot 1 \%)$ and nine cases among all referents $(5.6 \%)$. The percentages of diabetes were $11.0 \%$ in the high TCDD group, $2.4 \%$ in the low TCDD group, and $14.3 \%$ among referents. The corresponding percentages for benign and unspecified neoplasms were: $24 \cdot 7 \%, 15 \cdot 3 \%$, and $16 \cdot 8 \%$ respectively. Chronic liver disease was marginally higher in the high TCDD group: $31.5 \% v 21.2 \%$ in the low TCDD group and $23.0 \%$ among referents. Ischaemic heart disease percentages were unrelated to TCDD concentration.

Table 5 summarises illness rates according to TCDD concentration across and within chloracne subgroups. Overall rates increased with higher TCDD concentration in total and within each of the chloracne subgroups. The pattern was similar for infectious and parasitic diseases, disorders of the stomach and duodenum, and several other categories, but not for the respiratory disease categories and mental disorders. These last categories were raised in association with chloracne state but not consistently with high TCDD concentration.

\section{Discussion}

In this study, overall illness rates were positively correlated with prior chloracne state and were increased with higher TCDD concentration within the chloracne subgroup. Increased rates were found throughout the observation period and not just in the early years after exposure. Rates were notably higher in the severe chloracne group overall and for infectious and parasitic diseases, several respiratory disease categories, disorders of the peripheral nervous system and sense organs, mental disorders, and for other skin diseases. Consistency was shown for some disease categories but not for others when the data were subcategorised by back calculated TCDD concentration. For example, episodes due to mental disorders were associated with chloracne state but not high TCDD concentration.

Findings were positive for the skin, thyroid, immune system, and the central as well as the peripheral nervous system. Increased morbidity due to dermatological conditions occurred mainly in the severe chloracne subgroup. The absence of any insurance diagnoses attributable to diseases of the sebaceous glands in the no chloracne group indicates that either this subgroup was resistant to acne or that any existing acne among exposed workers had been classified as chloracne in the occupational medical records.

Eleven subjects were diagnosed with thyroid disease in the TCDD cohort and only two in the referent group. Unspecific goitre was reported in four exposed and the two referent cases. Four cases of thyrotoxicosis, two cases of hypothyroidism, and one case of another thyroid disorder were found among TCDD exposed workers. These cases were evenly distributed across chloracne subgroups, but were somewhat more likely to occur in the high TCDD group. Both cases of hypothyroidism occurred in workers with a high TCDD concentration and moderate to severe chloracne. A single case of thyroid adenoma was also reported in the severe chloracne, high TCDD, subgroup. Concerns about possible TCDD effects on thyroid function have been raised based on mechanistic arguments and experimental studies. ${ }^{11-13} \mathrm{~A}$ clear understanding of the mechanisms through which TCDD could influence the complex thyroid regulatory system and how these effects might be expressed as human disease is presently lacking. McKinney and Pedersen have modelled the effect of TCDDlike materials competing for thyroid hormone binding sites and have suggested that this could lead to varying degrees of hypothyroidism. ${ }^{14}$ Thyroid hormone economy could also be disrupted by increased metabolism due to hepatic microsomal enzyme induction. ${ }^{15}$ Capen also discussed how loss of thyroid hormone economy could lead to chronic hypersecretion of thyroid stimulating hormone (TSH) and an increased incidence of follicular cell tumours. ${ }^{15}$ The Ah-receptor mediated toxicity of TCDD could also play a part, for instance, through induction of thyroxin binding globulin (TBG) synthesis in the liver. We have shown TBG to be positively associated with internal TCDD dose in this same population. ${ }^{16}$ Serum thyroxine was also increased and marginal increases in both TSH and serum thyroxine were found among older workers with back calculated TCDD concentrations above 1000 ppt.

Our findings of increased morbidity due to infectious and parasitic diseases in the severe chloracne subgroup and in the high TCDD group are consistent with reduced host resistance, but may also reflect differences in insurance utilisation. Within the severe chloracne subgroup, much of the overall difference was accounted for by one disease subcategory, ill defined intestinal infections. Within this subcategory there were 37 episodes among 15 different people in the severe chloracne subgroup and only 13 episodes among 10 different people in the referent group. More episodes involving mycoses, particularly tinea pedis (athlete's foot) were also reported among those exposed to TCDD. For most other infectious diseases there were no notable differences in the frequency of diagnosis. There were five workers 
in the high TCDD group diagnosed with tuberculosis or late effects of tuberculosis compared with no cases among employees in the low TCDD group and three cases among all referents. There were no specific diagnoses of disorders involving the immune mechanism (ICD-9 279) among either exposed employees or referents.

There was nearly a twofold differential in rates of upper respiratory tract infections between employees with severe chloracne and their referents. The relative rate differential held throughout the observation period, although absolute rates in both groups declined steadily over time. Upper respiratory tract infection rates were not consistently increased in the high TCDD subgroups, however. Again there is a possibility that differences in medical care utilisation rates between the exposed and referent groups could bias the findings. For example, those in the exposed group and, in particular, in the severe chloracne subgroup, may have been more prone than referents to seek medical attention either because of their concerns about long term sequelae from exposure or because of medical counselling.

By contrast with the findings for these two categories, the percentage of employees ever diagnosed with appendicitis was increased across all chloracne subgroups. The 26 cases were nearly equally distributed by subgroup, but tended to occur in the earlier time periods. There were 23 exposed $v$ five referent cases before 1970 and three exposed $v$ four referent cases after that date. Within each chloracne subgroup, cases were more likely among men with estimated TCDD concentrations above $1000 \mathrm{ppt}$. The relevance of these findings to exposure to TCDD is unclear. Generally, the diagnosis of appendicitis should be verified histologically and this was not possible here. The intestine plays a part both in metabolising xenobiotics and in immunological protection of the host. Because faeces possibly containing lipid soluble compounds may remain much longer in the appendix than in the intestinal lumen and the concentration of immunocompetent tissue is very high in the appendix, these unanticipated findings would be plausible if TCDD was specifically toxic to this tissue. Other mechanisms of action may also explain our findings. More important is the need to confirm the findings in other TCDD exposed populations.

In all exposure subgroups and among the referents, there was no indication of an interaction between the occurrence of appendicitis and that of either upper respiratory tract infections or other infectious diseases. In other words, the occurrence of upper respiratory tract infections was independent of whether or not the same person had been diagnosed with appendicitis. There were also no differences in rates of influenza among the exposure subgroups. A somewhat higher pneumonia rate based on 17 cases was seen in the severe chloracne group: $1 \cdot 1 v 0.6$ episodes per 100 person-years among referents. The corresponding rate for the high TCDD group was 1.0 episodes per 100 person-years.

Although there have been several clinical investigations of immune system indices (for example, lymphocyte subset populations, immunoglobulins, and delayed hypersensitivity tests), we are unaware of human studies that have specifically examined infectious disease rates in exposed populations. There have been some reports correlating respiratory symptoms and the concentration of polychlorinated biphenyls in blood. ${ }^{17}{ }^{18}$ It is generally difficult to show immunotoxic effects of xenobiotics on occurrence of infectious disease because of a remarkable functional reserve capacity in immune response. ${ }^{19}$ Although our findings are not consistent across a range of infectious diseases, it is also difficult to attribute all the positive findings to confounding or observation bias.

Regarding mental diseases and peripheral nervous system diseases, increased episodes of illness for the total exposed cohort were seen only for disorders of the peripheral nervous system and sense organs. Review of diagnoses in this category showed that $13 \%$ of the exposed group episodes were for repeat occurrences of trigeminal nerve disorder in one worker from the severe chloracne subgroup. Eye and ear disorders accounted for about $50 \%$ of the total episodes. There was only one diagnosis of peripheral neuropathy (ICD-9 356) in the severe chloracne subgroup and this person was also diagnosed as diabetic. Our findings are thus consistent with the results of cross sectional studies of TCDD exposed workers, which found no evidence of increased occurrence of peripheral neuropathy..$^{21}$

Within the severe chloracne subgroup there was a statistical increase in episodes due to mental disorders. More than $50 \%$ of the episodes related to ICD-9 306, a category including physiological malfunction arising from mental factors but not secondary to psychiatric disorders. The individual episodes were spread across subjects rather than being concentrated in only a few people. Some employees with severe chloracne have been subject to both persistent and disfiguring lesions. This could explain the association with severity of chloracne but not with high TCDD concentration itself. Taken as a whole, the pattern of mental and peripheral nervous system disorders seen in this study provides no concrete evidence linking specific pathological entities to TCDD exposure but suggests that more frequent episodes of a broad range of mental or nervous system disorders may be linked to high TCDD exposure.

Among other disease categories the most noteworthy finding was a marginal increase in benign and unspecified neoplasms within the severe chloracne subgroup. The 13 cases included one adenoma of the thyroid, one angioma, four neoplasms of the digestive system (three benign and one of uncertain behaviour), and seven neoplasms of unspecified sites (one benign and six of unspecified 
nature). Only one of these 13 employees was later diagnosed with a malignant neoplasm (a leukaemia). There was no significant increase in the number of malignant neoplasms in the total population or in any of the subgroups. In the earlier mortality study, an increase of malignancy related deaths was seen among those with chloracne allowing for a 20 year latency. ${ }^{6}$

Questions have been raised about TCDD causing liver disease, ulcer, ischaemic heart disease, and disorders of lipid metabolism as well as diabetes. For ulcer and diabetes we found no increased frequency of occurrence within the total exposed population, no increasing frequency with chloracne severity, and the high TCDD group had no increases relative to controls. For ischaemic heart disease there were no differences based on exposure state, severity of chloracne, or concentration of TCDD. Three of the five cases of disorders of lipid metabolism in the combined study and referent groups did occur among men in the high TCDD group. For chronic liver disease there were marginal increases in the percentage of cases in the total exposed group, in the moderate and severe chloracne subgroups, and in the high TCDD group. It is not possible, however, to draw firm conclusions from these limited findings. A proper interpretation of this study can only be made in the light of findings from the mortality study, which is currently being updated, and clinical laboratory studies, which are also being completed among surviving members of the study population.

We thank Professor Sir Richard Doll, Oxford, England and Professor Harvey Checkoway, Seattle, Washington USA, for their comments and suggestions regarding our draft manuscript and Mr Schimbeno and his staff with the BASF Health Insurance Fund for abstraction and coding of the medical insurance data.

1 NN. Hautschädigungen durch unbekannte Zersetzungsprodukte. BASF, Ludwigshafen. Arbeitsschutz im Werk 1954;3:11-2.

2 Hoffmann H. Neue Erfahrungen mit hochtoxischen Chlorkohlenwasserstoffen. Archiv fur experimentelle Pathologie und Pharmakologie 1957;232:228-30.
3 Goldmann P. Schwerste akute Chlorakne durch Trichlorphenol-Zersetzungsprodukte. Arbeitsmedizin, Sozialmedizin, Arbeitshygiene 1972;7:12-8.

$4 \mathrm{Kimmig}$ J, Schulz KH. Chlorierte aromatische zyklische Äther als Ursache der sogenannten Chlorakne. NaturAther als Ursache der sogen
wissenschaften 1957;44:337-8.

5 Thiess AM, Frentzel-Beyme R, Link R. Mortality study of persons exposed to dioxin in a trichlorphenol-process
piess AM, Frentzel-Beyme R, Link R. Mortality study of accident that occurred in the BASF AG on Novembe 17, 1953. Am $\mathcal{F}$ Ind Med 1982;3:179-89.

6 Zober A, Messerer P, Huber P. Thirty-four-year mortality follow-up of BASF employees exposed to $2,3,7,8$ TCDD after the 1953 accident. Int Arch Occup Environ Health 1990;62:139-57.

7 Ott MG, Messerer P, Zober A. Assessment of past occupational exposure to $2,3,7,8$-TCDD using blood lipid analysis. Int Arch Occup Environ Health 1993;65:1-8.

8 Pirkle JL, Wolfe WH, Patterson DG, Needham LL Michalek JE, Miner JC, et al. Estimates of the half-life of Michalek JE, Miner JC, et al. Estimates of the half-life of 2,3,7,8-tetrachlorodibenzo-p-dioxin in Vietnam veterans of Operation Ranct

9 Suskind RR. Chloracne, "The hallmark of dioxin intoxication". Scand f Work Environ Health 1985;11:165-71.

10 Bond GG, McLaren EA, Brenner FE, Cook RR Incidence of chloracne among chemical workers potentially exposed to chlorinated dioxins. $\mathcal{F}$ Occup Med 1989; 31:771-4.

11 Potter CL, Moore RW, Inhorn SL, Hagen TC, Peterson RE. Thyroid status and thermogenesis in rats treated with 2,3,7,8-tetrachlorodibenzo-p-dioxin. Toxicol Appl Pharmacol 1986;84:45-55.

12 McKinney JD, Chae K, Oatley SJ, Blake CCF. Molecular interactions of toxic chlorinated dibenzo-p-dioxins and dibenzofurans with thyroxine binding prealbumin. $f$ Med Chem 1985;28:375-81.

13 Gorski JR, Muzi G, Wever LWD, Pereira DW, Arceo RJ, Iatropoulos MJ, Rozman K. Some endocrine and morphological aspects of the acute toxicity of 2,3,7,8-tetrachlorodibenzo-p-dioxin (TCDD). Toxicol Pathol 1988; 16:313-20.

14 McKinney JD, Pedersen LG. Do residue levels of polychlorinated biphenyls (PCBs) in human blood produce mild hypothyroidism? $\mathcal{F}$ Theor Biol 1987;129:231-41.

15 Capen CC. Pathophysiology of chemical injury of the thyroid gland. Toxicol Lett 1992;64-65:381-8.

16 Zober A, Ott MG, Messerer P, Germann C. Laboratory results for selected target organs in 138 individuals occupationally exposed to TCDD. presented to: Dioxin ' 93 pation international symposium on chlorinated dioxins and 13 th international symposium on chlorinated dioxins
related compounds, 20-24 September, Vienna, 1993.

17 Kuratsume M. Yusho, with reference to Yu-Cheng. In: Kimbrough RD, Jensen AA, eds. Halogenated biphenyls, terphenyls, naphthalenes, dibenzodioxins and related products. Amsterdam: Elsevier Sci Publ, 1989:381-400.

18 Shigematsu N, Ishimura S, Saito R, Ikeda T, Matsuba K, Sugiyama K, Masuda Y. Respiratory involvement in polychlorinated biphenyls poisoning. Environ Res 1978; 16:92-100.

19 Fischbein A, Tarcher AB. Disorders of the immune system. In: Tarcher AB ed. Principles and practice of environmental medicine. New York: Plenum Medical, 1992: mental 411 .

20 Sweeney MH, Fingerhut MA, Arezzo JC, Hornung RW, Conally LB. Peripheral neuropathy after occupational Conally LB. Peripheral neuropathy after occupational Am ₹ Ind Med 1993;23:845-58.

21 Alderfer R, Sweeney MH, Fingerhut MA, Patterson Jr DG, Turner WE, Conally LB, et al. Serum levels of PCDDs and PCDFs among workers exposed to 2,3,7,8TCDD contaminated chemicals. Chemosphere 1992;25: 247-50. 